\title{
Engine reconditioning workshops: lead contamination and the potential risk for workers: a pilot study
}

\author{
Matthew G James, Brian L Gulson
}

\begin{abstract}
Lead concentrations were measured in surface dust, airborne dust, air, and grinding material from five engine reconditioning workshops to evaluate the impact on blood lead concentrations (PbB) of 10 employees. Lead in the environmental samples ranged from trace amounts to extremely high concentrations $(4667 \mathrm{mg} /$ $\mathrm{m}^{2}$ ). The highest concentrations in surface wipes were found in areas where engine deposits are removed from valves and valve seats. The amounts of lead in long term dustfall accumulation and static air filter samples varied with the position in the workshop and the amount of ventilation. In all but one workshop, the air lead concentrations exceeded Australian occupational guidelines of $150 \mu \mathrm{g} \mathrm{Pb} / \mathrm{m}^{3}$. $\mathrm{PbB}$ ranged from 4.5 to $25.3 \mu \mathrm{g} / \mathrm{dl}$. There was an empirical relation between the cleanliness, work practices, ventilation of the workshops, lead concentrations in environmental samples and $\mathrm{PbB}$. Office employees not directly exposed to the leaded dust had the lowest PbB. Those who smoked had the highest PbB. Several relatively inexpensive recommendations were made to the owners to minimise exposure of the workers and in most cases these have been implemented.

(Occup Environ Med 1999;56:429-431)
\end{abstract}

Keywords: engine reconditioning; lead; environmental samples; blood; contamination; isotopes

Lead toxicity is a major public health concern and a primary environmental health issue. Industries that use lead in manufacturing or in the workplace - such as radiator repair workshops and car battery recycling operationsare legislated as lead industries to protect the workers from exposure to lead. ${ }^{12}$ The engine reconditioning trade is not classified as a lead process and hence neither workplace nor employees are monitored for lead exposure and there are no regulations about working practices - for example, the mandatory use of properly fitting respirators. About $15 \%$ of the lead from leaded petrol is retained in the engine. ${ }^{3}$ During engine reconditioning (valve grinding and valve reseating), metal grinding dust of variable particle size from the engine block is generated. Dispersal of lead dust particles throughout the workplace may pose a risk to the workers.

Engine reconditioning involves removal of the cylinder head from the vehicle, dismantling of the cylinder head including removal of the valves, a washing procedure to remove the deposits in the head, and grinding the valve seating in the head with a carborundum stone fitted to a drill (often powered by compressed air). Valves may be buffed with a bench grinder fitted with steel brushes and refaced (ground) on a valve facer fitted with a carborundum stone. These activities produce the bulk of the lead bearing dust as the other operations involve machines producing metallic particles, with cutting liquids an integral aspect of the process.

\section{Methods}

There are 94 registered engine reconditioning workshops in New South Wales in Australia. Environmental samples were collected from four workshops in the Sydney metropolitan area and another from a rural town. Blood sampling was only possible in the four Sydney workshops.

Environmental sampling comprised surface dust wipes, dustfall accumulation over 3 weeks, ${ }^{4}$ airborne dust with personal air samplers in static mode, and sweepings.

Blood samples were collected by venepuncture from active workers as well as office employees (controls). All subjects gave written informed consent to blood sampling.

Solubility tests used a 2 hour reaction of dust with $0.1 \mathrm{M} \mathrm{HCl}$ at $38^{\circ} \mathrm{C}$.

Wipes of each hand from one employee were obtained after the head grinding process.

A questionnaire was administered to each subject who gave a blood sample. Questions were especially targeted towards high risk activities, personal hygiene, smoking, and the possibility of taking home lead.

Approval was granted from the Macquarie University ethics committee.

All sample preparation and digestion was performed in a clean room. Environmental samples were prepared by standard 
Table 1 Personal information, blood lead concentration, and isotopic composition for employees

\begin{tabular}{lllllllll}
\hline $\begin{array}{l}\text { Workshop } \\
\text { subject }\end{array}$ & Sex & Age & $\begin{array}{l}\text { Years in } \\
\text { trade }\end{array}$ & Smoker & $\begin{array}{l}\text { Wash before } \\
\text { going home }\end{array}$ & $\begin{array}{l}\text { Wear work } \\
\text { clothes home }\end{array}$ & $\begin{array}{l}\text { Blood lead } \\
(\mu g / \text { dl) } t\end{array}$ & ${ }^{206} \mathrm{~Pb}{ }^{204} \mathrm{~Pb}$ \\
\hline A1 & Male & 43 & 29 & No & Yes & Yes & 9.5 & 16.97 \\
A2 & Male & 39 & $? ?$ & No & Yes & Yes & 4.5 & 16.97 \\
G1 & Male & 17 & 1 & No & Yes & Yes & 17.0 & 16.80 \\
G2 & Female & 48 & 15 & Yes & No & Yes & 5.1 & 16.76 \\
G3 & Male & 24 & 9 & Yes & Yes & Yes & 10.6 & 16.92 \\
G4 & Male & 45 & 20 & Yes & Yes & Yes & 25.3 & 17.23 \\
NR1 & Male & 22 & 3 & Yes & Yes & Yes & 6.0 & 17.00 \\
NR2 & Male & 35 & 15 & Yes & Yes & No & 9.0 & 17.06 \\
NR3 & Male & 50 & 20 & No & Yes & Yes & 5.9 & 16.98 \\
P1 & Male & 50 & 30 & No & Yes & No & 14.5 & 16.81 \\
\hline
\end{tabular}

^Office employee.

†Australian worksafe maximum is $50 \mu \mathrm{g} / \mathrm{dl}$.

techniques - for example, acid digestion - and lead concentrations were measured on a Varian Liberty 220 ICP-AES. Lead isotope ratios and lead concentrations were analysed by isotope dilution thermal ionisation mass spectrometry. $^{45}$

\section{Results}

Personal information about employees and $\mathrm{PbB}$ and isotope ratios are listed in table 1. A summary of the lead data for environmental samples is listed in table 2. Complete data sets are available from the second author.

\section{ENVIRONMENTAL SAMPLES}

Lead deposits on heads and valves were found to contain from $10 \%$ to $25 \% \mathrm{~Pb}$; high concentrations were still present in head deposits after cleaning.

The lead concentration in dust on various surfaces was extremely high with overall lead concentrations showing the following pattern: floor > general work benches > benches adjacent to grinders

The highest values of up to $1375 \mathrm{mg} / \mathrm{m}^{2} / 30$ days for dustfall accumulation were found in the grinding and sandblasting areas. In all but one workshop, airborne dust concentrations exceeded the Australian worksafe atmospheric exposure standard of $150 \mu \mathrm{g} \mathrm{Pb} / \mathrm{m}^{3} .^{2}$

\section{BLOOD SAMPLES}

Smokers had the highest, and office employees, the lowest $\mathrm{PbB}$ concentrations. The measured ${ }^{206} \mathrm{~Pb} /{ }^{204} \mathrm{~Pb}$ isotopic ratios in blood were within the range for the isotopic composition of petrol lead and particulates measured in Sydney from 1994 to the present with high volume air filters. ${ }^{6}$ Ratios for the office workers were similar to those of the exposed employees and indi- cate that the source of lead in all employees from the one workshop was the engine reconditioning process, regardless of occupation.

LEAD DUST ON HANDS

The hands, washed before grinding the head, contained 21500 and $38000 \mu \mathrm{g} \mathrm{Pb}$ per wipe for the right and left hand respectively. These concentrations probably represent a minimum amount of lead dust as they were for only one operation.

\section{Discussion}

The amounts of lead present in engine deposits can be extremely high with values of almost $36 \% \mathrm{~Pb}$ found on a valve. Hence in the reconditioning process, the amount of lead in dust can also be extremely high. In the high risk areas - such as valve grinding and facing, up to almost $18 \% \mathrm{~Pb}$ was measured in the floor dust.

The environmental measures show that a considerable amount of lead rich dust of small enough particle size to be airborne (and hence inhaled) is generated during engine reconditioning; air filter measurements, for all but one workshop, showed air lead concentrations that exceeded Australian occupational standards. ${ }^{2}$

Ingestion is also a major route either during the reconditioning operations or through transfer from unwashed hands, through smoking, or food consumption. The very high concentrations of lead up to $38000 \mu \mathrm{g} \mathrm{Pb} /$ hand on the hands of one worker undertaking the highest risk process of valve abrasion, is a potential source of ingested lead. These values are 50 times higher than for the boys living $<1 \mathrm{~km}$ from a lead smelter in Belgium. ${ }^{7}$

Another potential route is by skin absorption, ${ }^{8}$ especially during hot weather when there is maximum skin exposure and probably maximum sweat production.

Table 2 Lead concentrations of environmental samples

\begin{tabular}{|c|c|c|c|c|c|c|c|c|}
\hline \multirow{3}{*}{$\begin{array}{l}\text { Workshop } \\
\text { identifier }\end{array}$} & \multicolumn{2}{|l|}{ Wipes } & \multicolumn{2}{|c|}{ Grindings } & \multicolumn{2}{|c|}{ Petri dust } & \multicolumn{2}{|c|}{ Air filters $(8 \mathrm{~h})$} \\
\hline & Mean & Range & Mean & Range & Mean & Range & Mean & Range \\
\hline & \multicolumn{2}{|l|}{$\left(m g / m^{2}\right)^{\star}$} & \multicolumn{2}{|l|}{$(m g / g)$} & \multicolumn{2}{|c|}{ ( $\mathrm{mg} / \mathrm{m}^{2} / 30$ days) } & \multicolumn{2}{|l|}{$\left(m g / m^{3}\right) t$} \\
\hline A & $115(4)$ & $22-227$ & $1(2)$ & $0.017-2$ & $47(4)$ & $6.0-84$ & $2.5(2)$ & $2.0-3.0$ \\
\hline G & $320(5)$ & $25-1090$ & $10(3)$ & $0.15-30$ & $181(4)$ & $4.7-559$ & $1.0(3)$ & $0.3-2$ \\
\hline NR & $55(4)$ & $11.0-98$ & $13(3)$ & $0.24-38$ & $4.0(4)$ & $1.6-10$ & $0.3(2)$ & 0.3 \\
\hline $\mathrm{P}$ & $207(4) \ddagger$ & $27-411$ & $41(3)$ & $0.02-121$ & $31(4)$ & $7.0-79$ & $81(2)$ & $19-143$ \\
\hline Q & $2040(4)$ & $383-4667$ & $236(2)$ & $179-292$ & $162(2)$ & $10-313$ & $0.0447(2)$ & $0.0024-0.087$ \\
\hline
\end{tabular}

${ }^{\star}$ US HUD recommended clean up level after lead paint abatement $1.1 \mathrm{mg} / \mathrm{m}^{2}$.

†Australian worksafe maximum is $0.15 \mathrm{mg} \mathrm{Pb} / \mathrm{m}^{3}$ over $8 \mathrm{~h}$.

$\ddagger$ Number of samples analysed. 
In spite of the very high amounts of lead in the workshop environment and the soluble nature of the lead deposits, the $\mathrm{PbB}$ of the employees did not exceed the Australian occupational guidelines of $50 \mu \mathrm{g} / \mathrm{dl}$. Although in some cases they did exceed the National Health and Medical Research Council (NH and MRC) goal for all Australians of $10 \mu \mathrm{g} / \mathrm{dl}$.

There are other potential problems, which were not considered in this study. One is a possibility of the contamination of surrounding areas, as most of the ventilation systems from the workshops were external. Another is the potential of taking home leaded dust, as most workers did not change their clothes or shower before leaving the worksite.

In developed countries that have phased out leaded petrol - for example, the United States, Sweden, Japan), any potential contamination of engine reconditioning workshops would gradually diminish over time, and hence would not be classified as a lead industry. This, however, is not the case in many developing nations, where the overwhelming majority of motor vehicles are old and use leaded petrol.
We thank the workshop owners and their employees for participation and cooperation; Mary Salter for phlebotomy; Macquarie University for partial funding of this project; Jeff Davis for microscopical examination of some of the petri dusts; James Ray, Ann Sheehan, and Nicole Patison for assistance with analysis; Barry Batts (School of Chemistry) for access to the ICP-AES; and Dino Pisaniello of the Department of Community Medicine, University of Adelaide, for his assistance in preparing the questionnaire.

1 Tribe PW, Lead toxicity in a car radiator worker. Med $\mathcal{F}$ Aust 1997;166:53-4.

2 Worksafe Australia standard. Control of inorganic lead at work. Canberra: Australian Government Printing Service, 1994.

3 United States Environmental Protection Agency. Air Quality Criteria for Lead. Research Triangle Park, North Carolina, US EPA, 1996. (EPA Report No EPA/600/8-83/028aF.)

4 Gulson BL, Davis JJ, Mizon KJ, et al. Sources of lead in soil and dust and the use of dust fallout as a sampling medium. Sci Total Environ 1995;166:245-62.

5 Gulson BL, Howarth D, Davis JJ, et al. Lead bioavailability in the environment of children: blood lead levels in children can be elevated in a mining community. Arch Environ Health 1994;49:326-31.

6 Chiaradia M, Gulson BL, James M, et al. Identification of secondary lead sources in the air of an urban environment. Atmos Environ 1997;31:3511-21.

7 Roels HA, Buchet J-P, Lauwerys RR, et al. Exposure to lead by the oral and pulmonary routes of children living in the vicinity of a primary lead smelter. Environ Res 1980;22:8194.

8 Stauber JL, Florence TM, Gulson BL, et al. Percutaneous absorption of inorganic lead compounds. Sci Total Environ 1994;145:55-70. 